\title{
Geleneksel ve Fabrikasyon Yöntemiyle Üretilen İsot Baharatlarının Bazı Fizikokimyasal ve Renk Özelliklerinin Belirlenmesi
}

\author{
Aziz KORKMAZ ${ }^{1 *}$, Mustafa H. AYDOĞDU², Nusret MUTLU ${ }^{3}$, Ahmet Ferit ATASOY $^{1}$ \\ ${ }^{1}$ Harran Üniversitesi, Ziraat Fakültesi, Gıda Mühendisliği Bölümü, Şanlıurfa \\ ${ }^{2}$ Harran Üniversitesi, Ziraat Fakültesi, Tarım Ekonomisi Bölümü, Şanlıurfa \\ ${ }^{3}$ Kalkınma Bakanlığı, GAP Bölge Kalkınma İdaresi Başkanlığı, Şanlıurfa \\ *Sorumlu yazar: azizkorkmaz@harran.edu.tr
}

Öz

Bu çalışmada, geleneksel ve fabrikasyon metotlarla üretilen isot baharatlarının kalite özelliklerini belirleyen bazı fizikokimyasal ve renk özellikleri belirlenmiştir. Bu amaçla, rutubet oranı, su aktivitesi, $\mathrm{pH}$ değeri, titrasyon asitliği, toplam karotenoid içeriği, ekstrakte edilebilir renk (ASTA, k/s), esmerleşme indeksi ve yüzey renk parametreleri ölçülmüştür. Geleneksel ve Fabrikasyon isotların rutubet, pH, titrasyon asitliği ve $h^{\circ}$ değerlerinin aynı olduğu saptanmıştır. Buna karşın, fabrikasyon isotun su aktivitesi ve esmerleşme indeksinin daha yüksek olduğu tespit edilmiştir. Geleneksel isot toplam karotenoid miktarı, ASTA değeri, $\mathrm{k} / \mathrm{s}$ oranı ve yüzey renk değerlerinin de daha yüksek olduğu saptanmıştır. Çalışma sonuçları geleneksel isotun daha iyi bir renk kalitesine sahip olduğunu göstermiştir.

Anahtar kelimeler: Capsicum annuum, Urfa biberi, İsot baharatı, Renk kalitesi, Üretim yöntemi

\section{Determination of Some Physicochemical and Color Properties of Traditional and Industrial İsot}

\begin{abstract}
In this work, some physicochemical and color properties of traditional and industrial isot spices were determined. For this purpose, moisture content, water activity, $\mathrm{pH}$, titratable acidity, total carotenoid, extractable color (ASTA, k/s), browning index and surface color were measured. Among these features, the moisture, $\mathrm{pH}$, titratable acidity and $\mathrm{h}^{\circ}$ values of both isot spices were found as alike. However, water activity and browning index of traditional isot were lesser while total carotenoid, ASTA, r/s ratio and surface color values of this spice were higher. The results of this study show that the traditional isot has a better quality of color than the industrial isot
\end{abstract}

Key words: Capsicum annuum, Urfa pepper, Isot spice, Color quality, Production method

\section{Giriş}

Türkiye, kırmızıbiber (Capsicum annum L.) tarımında Dünyada Çin ve Meksika'dan sonra gelen önemli bir yetiştiricidir (Anonim, 2013a). Renk ve flora gibi başlıca duyusal özelliklerden ötürü kırmızıbiber taze, kurutulmuş, salça ve sos çeşitleri gibi farklı şekillerde yaygın olarak tüketilebilen bir sebzedir. Kırmızıbiberin ülkemizdeki en yaygın kullanım biçimlerinden biri de kurutularak baharat elde edilmesidir. Ülkemizde 2014 yılında sadece baharatlık biber üretimi için 200 bin ton civarında taze kırmızıbiber üretilmiş ve bu miktarın da yaklaşık \% 50'si Şanlıurfa ilinde yetiştirilmiştir (Anonim, 2015). Bu ilde hasat edilen kırmızıbiberler genellikle isot üretiminde kullanılmaktadır. Çeşni ve renk katmak 
amacıyla yemeklerde de tüketilen isot, kendine has koyu kırmızı rengi ve aromasından dolayı çiğ köfte ve lahmacun gibi yöresel gıda ürünlerinin hazırlanmasında önemli bir bileşen olarak kullanılmaktadır. Ayrıca, Şanlıurfa'da üretilen isot baharatı bu karakteristik özelliklerinden dolayı Türkiye Patent Enstitüsü tarafından 'Urfa isot biberi' olarak Coğrafi İşaret ile sertifikalandırılmıştır.

isot, geleneksel ve endüstriyel (fabrikasyon) olmak üzere iki farklı şekilde üretilebilmektedir. Geleneksel isot (Gi) üretiminde, tam olgunluğa gelmiş ve ayıklanmış taze kırmızıbiberler sap ve tohum yuvaları ayrılarak el ile 2-3 parçaya dilimlenir. Daha sonra, bu biber dilimleri ön kurutma, torbalarda bekletme (terletme), son kurutma ve öğütme olmak üzere dört farklı aşamadan geçirilerek isota dönüştürülmektedir. Bu üretimdeki kurutma ve terletme işlemleri beton bir zemin üzerinde ve güneş ışığı altında gerçekleştirilmektedir. Biberler istenen koyu kırmızı veya mor rengini de terletme aşamasında kazanır. Öğütme işleminden sonra, duyusal kaliteyi geliştirmek amacıyla isteğe bağlı olarak belli oranda zeytinyağı ve tuz da katılabilmektedir. Gi baharatının üretim süreci sezonun iklim şartlarına bağlı olarak ortalama 8-10 gün sürebilmektedir. Fabrikasyon isot (Fi) üretiminde ise, üretim daha hızı gerçekleşmektedir. Bu üretimde, belli bir rutubet oranına kadar $(<\% \quad 15)$ güneşte veya fırın ısıtıcılarla kurutulan biber dilimleri öncelikle öğütülüp pul biber haline getirilmektedir. Daha sonra bu pul biberlere \% 25-27 oranında rutubet içerek şekilde su katılır (tavlama) ve vida biçimindeki bir helezondan geçirilerek sürtünme yoluyla 60$65^{\circ} C^{\prime}$ ye kadar ısıtılmaları sağlanır. Bu şekilde ısıtılan biberler ahşaptan yapılmış ve ısıya karşı yalıtımlı havuzlara alınarak bekletmeye alınır. Kepertme olarak adlandırılan bu işlem sırasında biberlerin sıcaklığı 80-90 ${ }^{\circ} \mathrm{C}^{\prime}$ ye kadar yükselmektedir. Havuzlarda 30-36 saat bekletildikten sonra rutubet oranı tekrar azalan $(<\% 15)$ biberler havuzlardan çıkarılarak havalandırılır ve isteğe göre yağ ve tuz katılarak hazır hale getirilir. Kepertme işlemindeki temel amaç, geleneksel üretimde olduğu gibi, biberlerin daha koyu bir renk almasını sağlamaktır.

Günümüzde, her iki yöntemle üretilen biberler pazara isot olarak sunulsa da $\mathrm{Gi}$ pazarda daha yüksek fiyattan alıcı bulabilmektedir. Bu durum baharatlık kalitesi ve buna bağı olarak tüketici beğenisi ile açıklanmaktadır (Atasoy ve ark., 2016). Biber (Capsicum) baharatlarında duyusal kaliteyi etkileyen özelliklerin başında renk ve aroma gelmektedir. Özellikle renk faktörü son ürünün ticari kalitesinin belirlenmesinde ve nihai tüketicinin seçim yapmasında kritik bir öneme sahiptir (Nieto-Sandoval ve ark., 1999; Vega-Galvez ve ark., 2009). Ancak, isot biberlerindeki renk benzerliği duyusal olarak birbirinden ayırt edilmelerini de zorlaştırmaktadır. Bu durum, üreticiler açısından sektörde haksız rekabete sebep olmakla birlikte tüketiciler açısında da taklit veya hile olarak kabul edilmektedir.

Farklı kurutma yöntemleriyle elde edilen biber baharatlarının rengiyle ilgili bugüne kadar çeşitli çalışmalar yapıımıştır. Ancak, isot biberinin renk kalitesiyle herhangi bir çalışma yapılmamıştır. Ayrıca, farklı yöntemlerle üretilen isot biberlerindeki duyusal renk benzerliği hem üreticiler hem de tüketiciler açısından bir sorun teşkil etmektedir. Bu nedenle, çalışmada geleneksel ve fabrikasyon metotlarla üretilen isot baharatlarının bazı fizikokimyasal özelliklerin ve renk kalitelerinin belirlenmesi ve bunların birbiriyle karşılaştırılması amaçlanmıştır. 


\section{Materyal ve Metot}

Materyal

Çalışma materyali olarak Urfa tipi Capsicum annuum L. İnan3363 çeşidi taze kırmızıbiber kullanılmıştır. Bu biber çeşidi, Şanlıurfa'da bulunan GAP Tarımsal Araştırma Enstitüsü Müdürlüğü'ne bağlı Talat
Demirören İstasyonundan 2014 yılı üretim sezonu biberlerinden temin edilmiştir. Bu çeşide ait biberler 11-12 cm uzunluğunda ve 4-5 cm genişliğinde olup dar-üçgen biçimindedir. 2. hasada ait ve yeterli olgunluğa gelmiş taze biberlerden yaklaşık 200 kg kullanılmıştır.

Taze kırmızıbiber

$(\approx 200 \mathrm{~kg}$, C. annuum L. İnan3363)

$\downarrow$

Yıkama, ayıklama

(sap ve tohumların ayrılması)

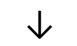

Kesme

(El ile 2-3 parça)

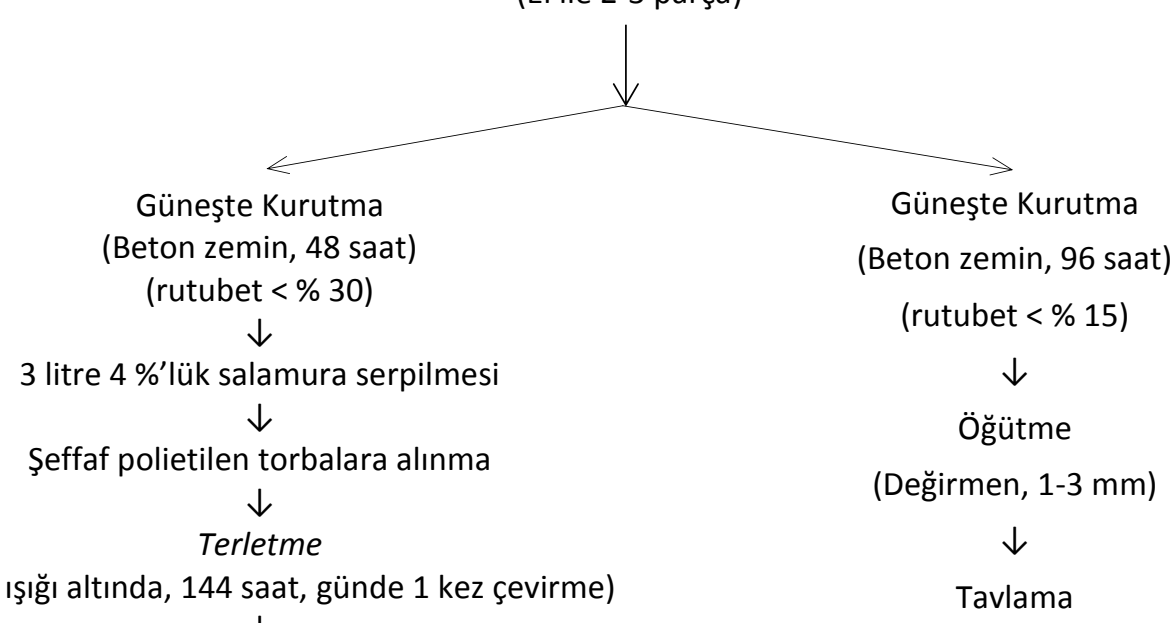

(güneşışığı altında, 144 saat, günde 1 kez çevirme)

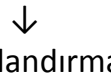

(Su serpme, rutubet \% 25-27)

(pamuk bez üzerinde, gece vakti, üretim süresince 2 kez)

$\downarrow$

Güneşte kurutma

(24 saat, rutubet $<\% 15$ )

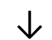

Öğütme

(Değirmen, 1-3 mm)

$\downarrow$

Geleneksel İsot (Gi)

\section{Isıtma}

(Sıkıştırma-sürtünme, $65^{\circ} \mathrm{C}$ )

$\downarrow$

Kepertme

$\left(85^{\circ} \mathrm{C}, 36\right.$ saat, rutubet $\left.<\% 15\right)$

$\downarrow$

Fabrikasyon İsot (Fi)

Şekil 1. Geleneksel ve fabrikasyon isot üretim akış şeması

Figure 1.The flow chart of production of traditional and industrial isot spices

Metot

Taze biberler 100'er kg olacak şekilde iki parçaya ayrılmıştır. Birinci kısım geleneksel isot, ikinci kısım ise fabrikasyon isot üretiminde kullanılmıştır. 


\section{Isot Baharatlarının Üretilmesi}

Gi üretimi için birinci grup taze kırmızıbiberler ayıklanıp yıkandıktan sonra sap ve tohum yuvalarından ayrılmıştır. Daha sonra, el yardımıyla 2-3 parçaya kesilen biberler temizlenmiş haldeki beton bir zemine serilerek güneşte kurutulmaya bırakılmıştır. Rutubet oranı \% 30'un altına kadar azalan (48 saat) biberlere terletme işlemi için 3 litre tuzlu su (\% 4 tuz) serpilerek polietilen torbalara alınmıştır. Bu işlemde, ağzı kapalı torbalardaki biberler 10-15 cm kalınlığa sahip olacak şekilde beton zemin üzerinde yayılarak güneş ışığı altında tutulmuştur. Kullanılan malzeme ve nemin etkisiyle torbaların iç sıcaklığının dış havaya göre yüksek olduğu belirlenmiştir. Bu artışın tespit edilmesi amacıyla torbaların iç sıcaklığı yine gece (saat 00:00), sabah (saat 06:00) ve öğlen (saat 12:30) olmak üzere her gün düzenli olarak üç defa ölçülmüştür. Torba içindeki ortalama sıcaklıklar gündüz ve gece vakitlerinde sırasıyla $50 \pm 1$ ve $23 \pm 1{ }^{\circ} \mathrm{C}$ olarak ölçülmüştür. Her gün bir defa çevrilen torbaların sıcak tutulması amacıyla gece vakitlerinde üstleri bir bezle örtülmüştür. Bazı gecelerde (toplam sürede 2 defa) biberler torbalardan çıkarılarak pamuktan yapılmış temiz bir bez üzerine serilerek gece boyunca havalandırılmıştır. Biberler istenen koyu rengi alınca (144 saat sonra) terletme süreci sonlandırılmış ve biberler bir gün (24 saat) daha açıkta temiz bir bez üzerinde kurutulduktan sonra değirmende ögütülmüştür.

Fabrikasyon isot (Fi) üretiminde ise, ayıklanmış, temizlenmiş ve dilimlenmiş ikinci grup taze biberler önce güneşte kurutularak pul bibere dönüştürülmüştür. Daha sonra bu kırmızı pul biberler rutubet oranı \% 25-27 olacak şekilde tavlama işlemine tabi tutulmuş ve biberler helezonik bir vida yardımıyla sıkıştırılarak sürtünme yoluyla $65^{\circ} \mathrm{C}^{\prime}$ ye kadar ısıtılmıştır. Bu şekilde ısıtılan biberler ahşap bir havuza alınarak yalıtımlı bir şekilde bekletilmiştir. Kepertme olarak anılan bu işlemde biberlerin sıcaklığının $85{ }^{\circ} \mathrm{C}^{\prime}$ ye kadar yükseldiği görülmüştür. 36 saat sonra rutubet oranının düşmesi $(<\% 15)$ ve rengin koyulaşmasına bağlı olarak kepertme işlemi sonlandırılmış ve biberler havuzdan çıkarılarak havalandırımıştır. Geleneksel ve fabrikasyon isot üretimlerine ait ayrıntılı akış şeması Şekil 1'de gösterilmiştir. Üretimler iki tekerrürlü olarak yapılmıştır.

\section{Fizikokimyasal Analizler}

Rutubet oranı, AOAC (2005b) metodu kullanılarak belirlenmiştir. Örneklerin su aktivitesi değerleri su aktivitesi tayin cihazı (Novasina, LabTouc-aw, Lachen, İsviçre) ile ölçülmüştür. Titrasyon asitliği ve $\mathrm{pH}$ değeri Serrano ve ark. (2010)'a göre belirlenmiştir.

\section{Renk Analizleri}

Toplam karotenoid analizinde ekstraksiyon işlemi Minguez-Mosquera ve Hornero-Mendez (1993) metoduna göre yapılmıştır. Toplam karotenoid içeriği, hazırlanan pigment ekstraksiyonunun spektrofotmetrede (Libra S70, Biochrom, Ingiltere) 460 nm'deki absorbansı ölçülerek hesaplanmıştır. Sonuçlar standart olarak kullanılan $\beta$-karoten cinsinden $\mathrm{mg} \mathrm{kg}^{-1}$ kurumadde olarak ifade edilmiştir (Gao ve ark., 2000). Ekstrakte edilebilir renk olarak ASTA (American Spice Trade Assocation) değeri AOAC (2005a)'a göre belirlenmiştir. Kırmızılık/sarılık (k/s) oranı ve esmerleşme indeksi Topuz ve ark. (2009)'un kullandığı metoda göre hesaplanmıştır. Yüzey (yansıyan) renk parametrelerinin ölçümleri chroma metre cihazıyla (Konica Minolta CR-5, Tokyo, Japonya) CIE renk koordinat sistemine göre yapılmıştır. Örneklerin renk değerleri $L^{*}$ (beyazlık-siyahlık), a* (kırmızlık-yeşillik) ve b* (sarılık-mavilik) değerleri ile ifade edilmiştir. 
$\mathrm{Bu}$ renk parametrelerine ilaveten, aşağıdaki denklemlere göre hesaplanan C (Yoğunluk) ve $\mathrm{h}^{\circ}$ (renk açısı) değerleri de cihaz tarafından ölçülmüştür (Vega-Galvez ve ark., 2009).

$C$ (Chroma) $=\left(a^{* 2}+b^{* 2}\right)^{0.5}$

$h^{\circ}$ (Hue angle) $=\tan ^{-1}\left(b^{*} / a^{*}\right)$

\section{istatistiksel analiz}

Bütün analizler üç paralelli olarak yapılmıştır. İstatistiksel analizler SPSS paket programıyla Yapar (2015)'a göre yapılmış ve ortalamalar arasındaki farklar Duncan Çoklu Karşılaştırma testine tabi tutulmuştur.

\section{Araştırma Bulguları ve Tartışma}

\section{Fizikokimyasal Özellikler}

Geleneksel ve fabrikasyon isot baharatlarının rutubet oranları, su aktiviteleri, $\mathrm{pH}$ değerleri ve titrasyon asitliği verileri Çizelge 1'de verilmiştir.

Geleneksel ve fabrikasyon isot baharatlarının rutubet miktarları sırasıyla \%14.31 ve \%13.41 olarak belirlenmiştir. Bu rutubet oranları Türk Gıda Kodeksi Baharat Tebliği'nde belirtilen maksimum rutubet miktarıyla uygunluk göstermektedir (Anonim, 2013b). Ancak, bu miktarlar arasındaki fark istatistiki olarak önemli bulunmamıştır ( $P>0.05)$. Buna karşın, isot biberlerinin su aktivitelerinin önemli düzeyde farklılık gösterdiği saptanmıştır $(\mathrm{P}<0.05)$. Gi'nin su aktivitesi 0.285 iken Fi'de bu değer 0.455 olarak ölçülmüştür.

Çizelge 1. Geleneksel ve fabrikasyon isot baharatlarının fizikokimyasal özellikleri*

Table 1. Physicochemical properties of traditional and industrial isot spices

\begin{tabular}{|c|c|c|}
\hline \multirow{2}{*}{$\begin{array}{l}\text { Özellik } \\
\text { Properties }\end{array}$} & \multicolumn{2}{|c|}{$\begin{array}{l}\text { Örnek } \\
\text { Sample }\end{array}$} \\
\hline & Gi & $\mathrm{Fi}$ \\
\hline $\begin{array}{l}\text { Rutubet }(\%, w / w) \\
\text { Moisture, }(\%, w / w\end{array}$ & $14.31 \pm 0.65^{a}$ & $13.41 \pm 0.26^{\mathrm{a}}$ \\
\hline $\begin{array}{l}\text { Su aktivitesi, aw } \\
\text { Water activity, aw }\end{array}$ & $0.285 \pm 0.003^{b}$ & $0.455 \pm 0.003^{a}$ \\
\hline $\begin{array}{l}\mathrm{pH} \\
\mathrm{pH}\end{array}$ & $4.66 \pm 0.02^{\mathrm{a}}$ & $4.49 \pm 0.02^{\mathrm{a}}$ \\
\hline $\begin{array}{l}\text { Titrasyon asitliği }(\%, v / w) \\
\text { Titratable acidity }(\%, v / w)\end{array}$ & $4.419 \pm 0.167^{a}$ & $4.073 \pm 0.146^{a}$ \\
\hline
\end{tabular}

Fi ve Gi baharatlarının rutubet oranlanın kırmızı pul biberlerden yüksek; su aktivitesinin ise düşük olduğu belirlenmiştir (Ağaoğlu, 1999). Paprikanın su aktivitesine göre Gi'nin daha düşük olduğu, Fi'nin ise paprikadan daha yüksek su aktivitesine sahip olduğu (Ordonez-Santoz ve ark., 2014) saptanmıştır. Gıdaların kurutulmasında temel amaç düşük su aktivitesiyle etkin bir muhafaza sağlayabilmektir (Arslan ve Özcan, 2011; Vega-Galvez ve ark., 2009). Biberlerin kurutularak baharata işlenmesinde son ürünün su aktivitesi değeri, kullanılan üretim veya kurutma metoduna göre değişebilmektedir (Ramesh ve ark., 2001). Çalışmamızda, Fi'nin daha yüksek $a_{w}$ değerine sahip olmasının, yüksek sıcaklığın $\left(85^{\circ} \mathrm{C}\right)$ hücre yapısında meydana getirdiği zarara 
bağlı olarak biberlerin ozmotik özelliklerinde de meydana getirdiği değişimlerle ilintili olduğu düşünülmektedir (Vega-Galvez ve ark., 2009). Ayrıca, geleneksel üretim sırasında katılan tuzlu suyun da Gi'nin daha düşük su aktivitesine sahip olmada etkili olduğu düşünülmektedir (Papageorge ve ark, 2003).

Geleneksel ve fabrikasyon isotlarının $\mathrm{pH}$ değerleri sırasıyla 4.66 ve 4.49 olarak tespit edilmiştir. Titrasyon asitliğin de $\mathrm{Gi}$ ve $\mathrm{Fi}$ örneklerinde sırasıyla \%4.419 ve \%4.073 olduğu saptanmıştır. Titrasyon asitliği ve $\mathrm{pH}$ değeri bakımından isotlar arasından önemli bir fark bulunmamıştır ( $P>0.05)$. $\mathrm{pH}$ değeriyle ilgili sonuçlar Toontom ve ark. (2012)'nın yaptığı çalışma sonuçlarıyla paralellik gösterirken, titrasyon asitliğiyle ilgili sonuçlarımızın hem bu çalışma ve hem de diğer bir çalışma (Vega-Galvez ve ark., 2009) sonuçlarına göre daha yüksek olduğu belirlenmiştir. Isot baharatlarında titrasyon asitliğinin yüksek olması kurutma sırasındaki mikrobiyal faaliyetin bir sonucuyla ilgili olduğu tahmin edilmektedir (GallardoGuerero ve ark., 2010; Toontom ve ark., 2012).

\section{Renk Özellikleri}

Geleneksel ve fabrikasyon isot biberlerinin toplam karotenoid içerikleri, ASTA değerleri, $\mathrm{k} / \mathrm{s}$ oranları ve esmerleşme indeksleriyle ilgili veriler Çizelge 2 'de verilmiştir.

Çizelge 2. Geleneksel ve fabrikasyon isot baharatlarının renk özellikleri*

Table 2. The color features of traditional and industrial isot spices

\begin{tabular}{|c|c|c|}
\hline \multirow{2}{*}{$\begin{array}{l}\text { Özellik } \\
\text { Properties }\end{array}$} & \multicolumn{2}{|c|}{$\begin{array}{l}\text { Örnek } \\
\text { Sample }\end{array}$} \\
\hline & Gi & Fi \\
\hline $\begin{array}{l}\text { Toplam Karotenoid }\left(\mathrm{mg} \mathrm{kg}^{-1} \mathbf{K M}^{1}\right) \\
\text { Total carotenoid }\left(\mathrm{mg} \mathrm{kg}^{-1} \mathrm{KM} \mathrm{drw)}\right.\end{array}$ & $1191.74 \pm 3.14^{\mathrm{a}}$ & $816.60 \pm 11.80^{b}$ \\
\hline $\begin{array}{l}\text { ASTA } \\
\text { ASTA }\end{array}$ & $139.11 \pm 0.15^{\mathrm{a}}$ & $124.38 \pm 0.45^{b}$ \\
\hline $\begin{array}{l}\text { Kırmızılık/sarılık (k/s) } \\
\text { Redness/Yellowness (r/y) }\end{array}$ & $0.98^{a}$ & $0.95^{b}$ \\
\hline $\begin{array}{l}\text { Esmerleşme İndeksi (Ei) } \\
\text { Browning Index (BI) }\end{array}$ & $0.261 \pm 0.005^{b}$ & $0.713 \pm 0.013^{a}$ \\
\hline
\end{tabular}

\section{Toplam karotenoid}

Toplam karotenoid içeriği geleneksel isotta $1191.74 \mathrm{mg} \mathrm{kg}^{-1} \mathrm{KM}$, fabrikasyon yöntemle yapılan isotta ise $816.60 \mathrm{mg} \cdot \mathrm{kg}^{-1} \mathrm{KM}$ olarak bulunmuştur $(\mathrm{P}<0.05)$. isot örneklerinin toplam karotenoid miktarları literatürdeki bir çok çalışmanın verilerine göre daha düşük olduğu saptanmıştır (MinguezMosquera, 2000; Perez-Galvez ve ark., 2005; Topuz ve ark., 2011). Kırmızıbiber ve türevlerinin kurutma veya üretim sırasında karotenoid içeriğine bağlı rengin bozulması önemli bir kalite kaybı olarak kabul edilmektedir (Markus ve ark., 1999; Kim ve ark., 2004). Toplam karotenoid miktarıyla ilgili sonuçlarımızın önceki çalışma verilerinden daha düşük olmasında, isot üretimlerinde uygulanan sıcaklık-süre rejimlerinin karotenoidlerde meydana getirdiği bozunma düzeyiyle ilintili olduğu tahmin edilmektedir (Perez-Galvez ve Minguez-Mosquera, 2001; Gallardo-Guerrero ve ark., 2010). Ayrıca, 
fabrikasyon isot biberindeki daha düşük karotenoid içeriğinin, karartma için bu biberde uygulanan yüksek sıcaklığa bağlı olarak karotenoidlerde daha fazla düzeyde gerçekleşen termal bozunmadan kaynaklandığı düşünülmektedir (RodriguezAmaya ve ark., 2008).

\section{Ekstrakte edilebilir renk (ASTA)}

ASTA değeri geleneksel isot için 139.11, fabrikasyon isot için de 124.38 olarak tespit edilmiştir. Çalışmamızda elde edilen ASTA değerlerinin Kim ve ark. (2006) çalışmasından yüksek; Topuz ve ark. (2009) araştırmasından düşük olduğu belirlenmiştir.

Ekstarkte edilebilir renk olarak da bilinen ASTA değeri, çoğu zaman biberlerin karotenoid miktarı için bir gösterge olarak kabul edilmektedir (Vega-Galvez ve ark., 2009; Topuz ve ark., 2009). Bunun yanı sıra, ASTA değerlerimizin Hayoğlu ve ark. (2005) geleneksel ve fabrikasyon isot biberleri için bulduğu değerlerden daha düşük olduğu tespit edilmiştir.

Ekstrakte edilebilir rengin diğer bir ölçüsü de kırmızılık/sarılık (k/s) oranıdır. Geleneksel ve fabrikasyon isot/arının $\mathrm{k} / \mathrm{s}$ oranları sırasıyla 0.98 ve 0.95 olarak bulunmuştur. Geleneksel isotun $\mathrm{k} / \mathrm{s}$ değerinin Topuz ve ark. (2009)'un iki farklı biber çeşidi ve 4 farklı hızlı kurutmayla elde ettiği biberlerin $\mathrm{k} / \mathrm{s}$ değerleriyle benzerlik gösterdiği, ancak fabrikasyon isottaki $\mathrm{k} / \mathrm{s}$ değerinin bu çalışma verilerinden daha düşük olduğu saptanmıştır.

\section{Esmerleşme indeksi}

Biber baharatlarında renk kalitesini etkileyen diğer bir faktör de enzimatik olmayan esmerleşmedir. Çalışmamızda isot çeşitlerinin esmerleşme indekslerinin oldukça farklı sonuçlar sergilediği $(\mathrm{P}<0.05)$ ve bu indeksin geleneksel ve fabrikasyon örneklerinde sırasıyla 0.261 ve 0.713 olduğu tespit edilmiştir. Esmerleşme indeksine ait bu sonuçlar, pul biberiyle ilgili yapılan bir çok araştırmaların verilerine göre daha yüksek (Topuz ve ark., 2009) olmakla birlikte bazı çalışmaların verileriyle de örtüşmektedir (Rhim ve Hong, 2011). Renk kaybı olarak tanımlanan esmerleşmenin, isot biberinde spesifik rengin oluşabilmesi için belli bir düzeye kadar gerçekleşmesi arzu edilen bir durumdur. Kurutulmuş sebze ve meyvelerde esmerleşme, ısıya dayalı renk değişimleriyle açıklanmaktadır (Vega-Galvez ve ark., 2009). Biberlerde esmerleşmenin özellikle indirgen şeker ve amino asitler arasında meydana gelen Maillard tipi reaksiyonlardan kaynaklandığı belirtilmektedir (Lee ve ark, 1991). Bu reaksiyonların gerçekleşmesinde sıcaklık ve su aktivitesinin kilit rol oynadığı bildirilmektedir (Lee ve Park, 1989; Rhim ve Song, 2011;). Fi'nin Gi'den daha yüksek esmerleşme indisine sahip olmasının, üretimi sırasında uygulanan yüksek sıcaklık ve sahip olduğu yüksek su aktivitesine bağlı olduğunu düşünmekteyiz.

\section{Yüzey renk}

Gıda ürünlerinde rengin tanımlanmasında sıklıkla kullanılan bir yöntem de görünür algıları belirleyen yüzey veya yansıyan rengin ölçülmesidir. Bu ölçümde gıdanın sahip olduğu gerçek rengin tanımlanmasında Uluslararası Aydınlatma Komisyonu (International Commission Illumination, CIE) tarafından kullanılan ve kısaca CIElab olarak ifade edilen renk koordinat sistemidir (Anonim, 2016). Incelenen isot biberlerinin $L^{*}, a^{*}, b^{*}, C^{*}$ ve $h^{\circ}$ parametrelerine ait yüzey renk değerleri Çizelge $3^{\prime}$ te sunulmuştur.

Renk açısı $\left(h^{\circ}\right)$ hariç olmak üzere, bütün renk değerleri geleneksel isot baharatında daha yüksek bulunmuştur $(P<0.05)$. Bu sonuçlara göre, yüzey renk değeri yönünden geleneksel isot verilerinin önceki çalışma 
sonuçlarıyla paralellik gösterdiği, ancak fabrikasyon isodun yüzey renk değerlerinin bu çalışma verilerine göre daha düşük olduğu belirlenmiştir. (Rico ve ark., 2010; Valezguez ve ark., 2014).

Çizelge 3. Geleneksel ve fabrikasyon isot baharatlarının yansıyan renk özellikleri*

Table 3. The Characteristics of Surface Color of Traditional and industrial isot spices

\begin{tabular}{|c|c|c|}
\hline \multirow{2}{*}{$\begin{array}{l}\text { Yüzey Renk } \\
\text { Parametresi } \\
\text { Surface Color } \\
\text { Parameter }\end{array}$} & \multicolumn{2}{|c|}{$\begin{array}{l}\text { Örnek } \\
\text { Sample }\end{array}$} \\
\hline & Gi & Fi \\
\hline $\mathrm{L}^{*}$ & $51.64 \pm 0.19^{a}$ & $41.01 \pm 0.45^{b}$ \\
\hline$a^{*}$ & $17.04 \pm 0.63^{a}$ & $6.30 \pm 0.55^{b}$ \\
\hline$b^{*}$ & $19.14 \pm 0.44^{a}$ & $6.86 \pm 0.49^{b}$ \\
\hline$C^{*}$ & $25.63 \pm 0.74^{a}$ & $9.35 \pm 0.01^{b}$ \\
\hline$h^{\circ}$ & $48.33 \pm 0.39^{a}$ & $47.41 \pm 4.46^{a}$ \\
\hline
\end{tabular}

Yapılan çalışmalar, kurutulmuş biberde yüzey renk değerlerinin sıcaklık ve su aktivitesinden etkilendiği (Topuz, 2008); yüksek sıcaklığın daha koyu bir renk ve daha az kırmızılık ve sarılığa bağı renk bozulmasını tetiklediği belirtilmektedir (Rico ve ark., 2010). Fabrikasyon biberinin L* parametresinin daha küçük olmasına bağı olarak daha siyah bir renk yansitması bu biberin daha fazla oranda koyu renkli bileşiklerin içermesinin bir sonucu olarak değerlendirilmektedir. Benzer şekilde, kırmızı ve sarı renkleri belirten $a^{*}$ ve $b^{*}$ koordinatlarının geleneksel isot biberinin daha yüksek olması, bu baharatta rengi etkileyen karotenoid pigmentlerinin ve diğer bileşenlerin miktarıyla açıklanabilmektedir (Vega-Galvez ve ark., 2009).

\section{Sonuçlar}

Elde edilen bulgular ışığında, isotların renk özelliklerinin üretim yönteminden önemli düzeyde etkilendiği ve geleneksel isodun fabrikasyon isot baharatından oldukça farklı bir renge sahip olduğu belirlenmiştir. Isot üretiminde yüksek sıcaklığın duyusal rengi belirleyen faktörleri olumsuz etkilediği ve buna bağlı olarak fabrikasyon isot biberinde daha fazla esmerleşme ve daha düşük düzeylerde toplam karotenoid miktarı, ASTA değeri, $\mathrm{k} / \mathrm{s}$ oranı ve yüzey renk parametreleri tespit edilmiştir. Ayrıca, üretimden sonra bu biber baharatlarında meydana gelebilecek kalite kayıplarının ertelenebilmesi açısından geleneksel isotun daha ideal bir su aktivitesine sahip olduğu belirlenmiştir.

\section{Ekler}

Bu çalışma Harran Üniversitesi Bilimsel Araştırma Komisyonu (HÜBAK) (proje NO:14010) ve Türkiye Cumhuriyeti Kalkınma Bakanlığı Güneydoğu Anadolu Projesi Bölge Kalkınma idaresi Başkanlığı (GAP-ISOT) tarafından desteklenmiştir.

\section{Kaynaklar}

Ağaoğlu, S., 1999. Van ilinde açıkta satılan kırmızı pul biberlerde aflatoksin $B_{1}$ varlığının araştııılması. Van Tıp Dergisi, 6(4): 28-30.

Anonim, 2013a. http://faostat3.fao.org/downloa d/Q/QC/E. Erişim tarihi: 29.11.2015.

Anonim, 2013b. Türk Gıda Kodeksi Baharat Tebliği, Türk Gıda Kodeksi, Tebliğ No: 2013/12, Ankara.

Anonim, 2015. https://biruni.tuik.gov.tr/bitkisela pp/bitkisel.zul. Erişim tarihi: 10.09.2015.

Anonim, 2016. https://en.wikipedia.org/wiki/Lab color space. Erişim tarihi: 23.05.2016

AOAC, 2005a. Official Methods of Analysis, 18th edition, Association of Official Analytical Chemists. Arlington VA, USA.

AOAC, 2005b. Official methods of analysis, 19th edition, Association of Official Analytical Chemists. Washington DC, USA. 
Arslan, D., ve Özcan, M. M., 2011. Dehydration of red bell-pepper (Capsicum annuum L.): Change in drying behavior, colour and antioxidant content. Food and Bioproducts Processing, 89: 504-513.

Atasoy, A. F., Aydoğdu, M. H., Korkmaz, A., ve Kara, E., 2016. Urfa isot biberinin özelliklerinin belirlenerek pazar potansiyelinin artırılması. Tarımsal Araştırma Destekleri Proje Sonuç Raporu, GAP İdaresi Başkanlığı, Mart 2016, Şanlıurfa.

Gallardo-Guerrero, L., Perez-Galvez, A., Aranda, E., Minguez-Mosquera, M., I. ve HorneroMendez, D., 2010. Physicochemical and microbiological characterizaiton of dehydration processing of red pepper fruits for paprika production. LWT-Food Science and Technology, 43: 1359-1367.

Gao, X., Ohlander, M., Jeppsson, N., Bjork, L., ve Trajkovski, V., 2000. Changes in antioxidant effects and their relationship to phytonutrients in fruits of Sea buckthorn (Hippophae rhamnoides L.) during maturation. Journal of Agricultural and Food Chemistry, 48: 1485-1490.

Hayoglu, I., Didin, M., Turkoglu, H., ve Fenercioglu, $\mathrm{H} ., 2005$. The effects of processing methods on some properties of hot red and red-blackish ground pepper. Pakistan Journal of Biological Sciences, 8(10): 14201423.

Kim, S., Park, J. ve Hwang, I. K., 2004. Composition of main carotenoids in Korean red pepper (Capsicum annuum, L.) and changes of pigment stability during the drying and storage process. JFS: Food Chemistry and Toxicology, 69: 39-43.

Kim, S., Lee, K. W., Park, J., Lee, H. J., ve Hwang, I. K., 2006. Effect of drying in antioxidant activity and changes of ascorbic acid and colour by different drying and storage in Korean red pepper (Capsicum annuum, L.). International Journal of Food Science and Technology, 41: 90-95.

Lee, D-S. ve Park, M-H., 1989. Quality optimization in red pepper drying. Korean Journal of Food Science and Technology, 21: 655-661.

Lee, D. S., Chung, S. K., Kim, H. K. ve Yam, K., L., 1991. Nonenzymatic browning in dried red pepper products. Journal of Food Quality, 14(2):153-163.

Markus, F., Daood, H. G. Kapitany, J. ve Biacs, P. A., 1999. Change in the carotenoid and antioxidant content of spice red pepper (paprika) as a function of ripening and some technological factors. Journal of Agricultural and Food Chemistry, 47: 100107.

Minguez-Mosquera, M. I., ve Hornero-Mendez, D., 1993. Separation and quantification of the carotenoid pigments in red peppers (Capsicum annuum L.), paprika, and oleoresin by reversed phase HPLC. Journal of Agricultural and Food Chemistry, 41: 1616-1620.

Minguez-Mosquera, M. I., Perez-Galvez, A., ve Garrido-Fernandez, J., 2000. Carotenoid content of the varieties jaranda and jariza (Capsicum annuum L.) and response during the Industrial slow drying and grinding steps in paprika processing. Journal of Agricultural and Food Chemistry, 48: 29722976.

Nieto-Sandoval, J. M., Fernandez-Lopez, J. A., Almela, L. ve Munoz, J. A., 1999. Dependence between apparent color and extractable color in paprika. Color Research and Application, 24: 93-97.

Ordonez-Santos, I. E., Pastur-Garcia, B., RomeroRodriguez, A., ve Vazguez-Oderiz, L., 2014. Colour of hot paprika from the La Vera and Murcia regions packaged in different atmospheres during storage. International Journal of Food Science and Technology, 49: 217-223.

Papageorge, L. M., McFeeters, R. F., ve Fleming, H. P., 2003. Factors influencing texture retention of salt-free, acidified, red bell peppers during storage. Journal of Agricultural and Food Chemistry, 51: 14601463.

Perez-Galvez, A., ve Minguez-Mosquera, I., 2001. Structure-Reactivity relationship in the oxidation of carotenoid pigments of the Pepper (Capsicum annuum L.). Journal of Agricultural and Food Chemistry, 49: 48644869

Perez-Galvez, A., Hornero-Mendez, D., ve Minguez-Mosquera, M. I., 2005. Dependence of carotenoid content and temperature-time regimes during the traditional slow drying of red pepper for paprika production at La Vera county. European Food Research Technology, 221: 645-652.

Ramesh, M. N., Wolf, W., Tevini, D., ve Jung, G., 2001. Influence of processing parameters on the drying of spice paprika. Journal of Food Engineering, 49: 63-72. 
Rhim, J-W. ve Hong, S-I., 2011. Effect of water activity and temperature on the color change of red pepper (Capsicum annuum L.) powder. Food Science and Biotechnology, 20: 215-222.

Rico, C. W., Kim, G-R., Ahn, J-J., Kim, H-K., Furuta, M., ve Kwon, J-H., 2010. The comparative effect of steaming and irradiation on the physicochemical and microbiological properties of dried red pepper (Capsicum annum L.). Food Chemistry, 119: 10121016.

Rodriguez-Amaya, D. B., Kimura, M., Godoy, H., ve Amaya-Farfan, J., 2008. Updated Brazilian database on food carotenoids: Factors affecting carotenoid. Journal of Food Composition and Analysis, 21: 445-463.

Serrano, M., Zapata, P. J., Castillo, S., Guillen, F., Martinez-Romero, D., ve Valero, D., 2010. Antioxidant and nutritive constituents during sweet pepper development and ripening are enhanced by nitrophenolate treatments. Food Chemistry, 118: 497-503.

Toontom, N., Meenune, M., Posri, W., ve Lertsiri, S., 2012. Effect of drying on physical and chemical quality, hotness and volatile flavour characteristics of dried chilli. International Food Research Journal, 19(3): 1023-1031.

Topuz, A. 2008. A novel approach for color degradation kinetics of paprika as a function of water activity. LWT - Food Science and Technology 41: 1672-1677.

Topuz, A., Feng, H. ve Kushad, M., 2009. The effect of drying method and storage on color characteristics of paprika. LWT-Food Science and Technology,42: 1667-1673.

Topuz, A., Dincer, C., Ozdemir, K. S., Feng, H. ve Kushad, M., 2011. Influence of different drying methods on carotenoids and capsaicinoids of paprika (Cv., Jalapeno). Food Chemistry, 129: 860-865.

Valezguez, R., Hernandez, A., Martin, A., Aranda, E., Gallardo, G., Bartolome, T., ve Cordoba, M. G., 2014. Quality assessment of commercial paprikas. International Journal of Food Science and Technology, 49. 830839.

Vega-Galvez, A., Di Scala, K., Rodriguez, K., LemusMondaca, R., Miranda, M., Lopez, J. ve Perez-Won, M., 2009. Effect of air-drying temperature on physico-chemical properties, antioxidant capacity, colour and total phenolic content of red pepper
(Capsicum annuum, L. var. Hungarian). Food Chemistry, 117: 647-653.

Yapar, N., 2015. Kırmızıbiberlerde Aspergillus flavus'un gelişimi, aflatoksin üretimi ve biyosentez yolundaki bazı genlerin ekspresyon düzeyleri üzerine, su aktivitesi, sıcaklık ve zamanın etkisinin modellenmesi. Doktora Tezi, Erciyes Üniversitesi Fen Bilimleri Enstitüsü, Kayseri, 195s. 